\title{
Comparative Study between Drained and Drainless Sub-rectal Mesh Hernioplasty in Paraumbilical Hernia
}

\author{
Raouf Mahmoud Sallam, Ahmed Mohamed El-sayed, Abdou Mahmoud Abdou \\ Department of General Surgery, Faculty of Medicine, Al-Azhar University, Cairo, Egypt
}

Corresponding author: Abdou Mahmoud Abdou, Tel: 00201277700794, Email: abdoumahmoud1986@gmail.com

\begin{abstract}
Background: The evolution of para-umbilical hernia repair has a very long history, from the Recognition of para-umbilical hernias to its current management, with significant contributions from different authors. Advances in surgery have led to more cases of para-umbilical hernia formation, and this has required the development of new techniques and new materials for para-umbilical hernia management.

Objectives: To compare between the results of drained and drainless sub-rectal mesh hernioplasty in paraumbilical hernia (PUH), to achieve the most accepted post-operative condition.

Patient and methods: This comparative prospective study included a total of 50 patients with a follow up of 6-month time interval who were all complaining of an uncomplicated para-umbilical hernia and all are treated with the sub-lay repair technique with 25 patients with suction drain placement and 25 patients with no suction drain placement, attending at Al-Azhar University Hospitals.

Results: Sub lay (sub-rectal) mesh repair is a good alternative to other traditional repairs, this study advocates this method of Para-umbilical hernia repair as it is applicable type of repair, the complication rate is low and there is a no recurrence rate or seroma formation and suction drain usage on hazardous patients are beneficial to avoid fluid accumulation or further complication to occur.

Conclusion: Placing mesh in the sub-muscular or sublay position is claimed to be more challenging but not beyond the competence of a trained general surgeon. Placing mesh in this plane has mechanical and physiologic advantages. The sub-lay technique proves itself as one of the best surgical technique in management of para-umbilical hernia.
\end{abstract}

Keywords: Sublay, retromuscular, submascular and mesh.

\section{INTRODUCTION}

Para-Umbilical Hernia (PUH) is one of the most common surgical problems with rise in the repair rate annually ${ }^{(\mathbf{1}, \mathbf{2})}$.

Previously PUHs were repaired by tension-free suture technique. Due to a high unacceptable recurrence rate this procedure lost popularity ${ }^{(3)}$. Real change in view of PUH repair came with the introduction of meshplasty ${ }^{(4)}$.

Para-umbilical hernias are large abdominal defects through the linea alba in the region of the umbilicus and are usually related to diastasis of the rectus abdominis muscle ${ }^{(5)}$.

A para-umbilical hernia protrudes through the midline aponeurotic zone of the anterior abdominal wall. The detailed and critical reexamination of the functional anatomy of the rectus sheath and its contents are crucial not only to the understanding of the development of this hernia but also to the rational and optimal surgical management of the condition (6).

The general consensus regarding the development of a para-umbilical hernia is the weakening of the fabric of the midline aponeurotic zone by prolonged stretch (continuous as ascites or temporary as repeated pregnancy). The turn-key event for herniation is tearing of the medial attachment of the third tendinous intersection to the midline aponeurotic zone ${ }^{(7)}$.

Repetitive stress as a factor in hernia development is suggested by clinical presentations. Increased intra-abdominal pressure is seen in a variety of disease states and seems to contribute to hernia formation in 
these populations. Elevated intra-abdominal pressure is associated with chronic cough, ascites, peritoneal dialysis or ventriculoperitoneal shunts, intra-peritoneal masses or organomegaly, and constipation ${ }^{(8)}$.

The contour of the abdomen is dependent upon age, muscle mass, muscle tone, obesity, intra-abdominal pathology, parity and posture. These factors may significantly alter topography and become a major obstacle to a proper incision selection and placement ${ }^{(9)}$.

Incision and closure of the abdominal wall are among the most frequently performed surgical procedures, the abdominal wall are defined cranially by the xiphoid process of the sternum and the coastal margins, and caudally by the iliac and the pubic bones of the pelvis. It extends to the lumbar spines which joins the thorax and pelvis and is a point of structure ${ }^{(\mathbf{1 0})}$.

During the last few decades, the open surgical approach has been the standard technique for hernia repair. First it was done by sutures alone, which has several complications such as putting excessive strain on the surrounding tissues and also has high recurrence rate. In order to provide better results and to decrease these complications, an alternative technique was developed in which there is a piece of synthetic mesh or screen material is applied ${ }^{(\mathbf{1 1})}$.

Drainage tubes brought out through the operation wound are potent cause of postoperative hernias ${ }^{(\mathbf{1 2})}$.

Since the tissue planes along the track of the drain are not sutured, an open and weak passage is present through all the layers of the wound through which a hernia may develop. Furthermore, after the first few hours, there is a rapid rise in the wound infection rate, since the drain allows for two-way passage of secretions outwards and organisms inward to the wound and abdominal cavity. Also, the irritation caused by drain causes edema, softening, tearing of the tissues and cutting out of sutures ${ }^{(13)}$.

The aim of this study was to compare between the results of drained and drainless sub-rectal mesh hernioplasty in paraumbilical hernia (PUH), to achieve the most accepted post-operative condition and to help in decreasing the morbidity of complication and mortality rate down to zero.

\section{PATIENTS AND METHODS}

This comparative prospective study included a total of 50 patients with a follow up of 6-month time interval who were all complaining of an uncomplicated paraumbilical hernia and all are treated with the sub-lay repair technique with 25 patients with suction drain placement and 25 patients with no suction drain placement, attending at AlAzhar University Hospitals. Approval of the ethical committees of both the General Surgery Department, and the Faculty of Medicine of Al-Azhar the University and a written informed consent from all the subjects were obtained. This study was conducted between (the duration from March 2017, and June 2018).

Eligible participants were patients presenting with uncomplicated para-umbilical hernia (PUH). Patients with recurrent PUH were excluded. Data regarding age, gender, body mass index (BMI) and associated comorbidities were obtained from all patients. Following preoperative evaluation and preparation for surgery, patients were randomly assigned into two groups of which twenty-five patients to receive a drain tube and other twenty five will not receive the drain tube.

Data regarding age, gender, body mass index (BMI) and associated co-morbidities were obtained from all patients.

All patients were subjected to: Clinical evaluation including: History taking, General \& local examinations. Laboratory 
investigations including: Complete blood count, Liver function tests, serum creatinine level, Random blood glucose level. Radiological investigations including: Abdominal US, CXR, ECG and Echocardiography study.

Operative technique: All the patients were given $1 \mathrm{~g}$ 3rd generation cephalosporin antibiotic preoperatively at the time of induction and continued till the 5th postoperative day twice daily. The operation is preferred to be performed under general anesthesia. Hair should be liberally clipped from the abdominal area. Preparation and disinfectant of skin follow by either midline or transverse skin incision that is directly over the hernial defect. After incising the subcutaneous tissue, the sac is dissected and delineated then defect is opened. The Sac dissected and delineated and a plane is created between the posterior rectus sheath and the rectus muscle for the placement of the mesh. Creation of plane between posterior sheath and the rectus muscle. The posterior rectus sheath along with the peritoneum is closed with $(2 / 0)$ prolene suture. The mesh should overlap the midline by $5 \mathrm{~cm}$ laterally and the umbilicus vertically. It should therefore be a minimum diameter of $10 \mathrm{~cm}$. During the Peritoneal closure a prolene mesh tailored to the size and placed in the plane created behind the recti. The mesh is fixed by few interrupted (2/0) polypropylene sutures. The anterior rectus sheath is closed with continuous 1 polypropylene suture. Suction drain was inserted in 25 patients in the sub-rectus sheath. Closure of the rectus sheath, Closure of the subcutaneous tissue and skin by sub-cuticular sutures. Statistical analysis used for this study calculation is Fisher Statistic. (https://en.wikipedia.org/wiki/Fisher's_exact_t est).

\section{RESULTS}

In this study, 50 patients with a follow up of 6 month time interval is of which they are all complaining of an uncomplicated para- umbilical hernia and all are treated with the sub-lay repair technique with 25 patients with suction drain placement and 25 patients with no suction drain placement.

Table (1): According to the age and sex of the studied patients:

\begin{tabular}{|l|l|c|}
\hline \multicolumn{2}{|l|}{} & Total no. = 50 \\
\hline \multirow{2}{*}{ Age (years) } & Mean \pm SD & $46.80 \pm 8.26$ \\
& Range & $32-65$ \\
\hline \multirow{2}{*}{ Sex } & Females & $27(54.0 \%)$ \\
& Males & $23(46.0 \%)$ \\
\hline
\end{tabular}

The previous table shows that the age range comes in between 32 and 65 years old with mean of 46.80 and SD of \pm 8.26 and number of patients with respect to sex is 27 females (54\%) to 23 males (46\%).

Table (2): According to the comorbidities recorded.

\begin{tabular}{|l|l|c|}
\hline \multicolumn{2}{|l|}{} & No. (\%) \\
\hline \multirow{2}{*}{ Co-morbidities } & Negative & $16(32.0 \%)$ \\
& Positive & $34(68.0 \%)$ \\
\hline \multirow{2}{*}{ HTN } & Negative & $32(64.0 \%)$ \\
& Positive & $18(36.0 \%)$ \\
\hline \multirow{2}{*}{ Diabetic } & Negative & $48(96.0 \%)$ \\
& Positive & $2(4.0 \%)$ \\
\hline \multirow{2}{*}{ Arthritis } & Negative & $49(98.0 \%)$ \\
& Positive & $1(2.0 \%)$ \\
\hline \multirow{2}{*}{ COBD } & Negative & $39(78.0 \%)$ \\
& Positive & $11(22.0 \%)$ \\
\hline \multirow{2}{*}{ Chronic constipation } & Negative & $43(86.0 \%)$ \\
& Positive & $7(14.0 \%)$ \\
\hline \multirow{2}{*}{ Smoker } & Negative & $29(58.0 \%)$ \\
& Positive & $21(42.0 \%)$ \\
\hline
\end{tabular}

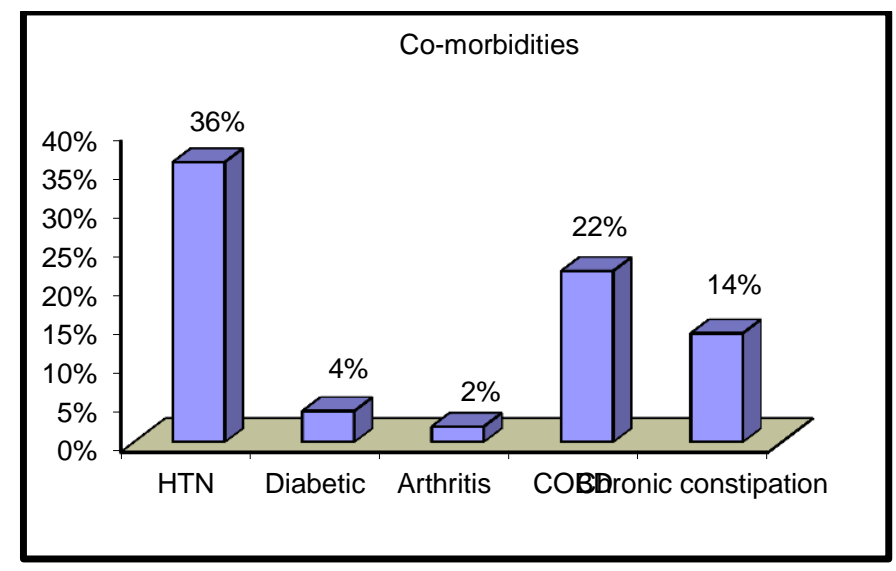

Figure (1): Co-morbidities.

Out of the 50 studied patients in this thesis 34 patients $(68 \%)$ have co-morbidities 
while $16(32 \%)$ patients have no significant co-morbidities. The most common comorbidities was HTN in 18 patients $(36 \%)$, diabetes in 2 patients (4\%), COPD in 11 patients $(22 \%)$, chronic constipation in 7 patients (14\%), arthritis in 1 patient (2\%) and 21 patients $(42 \%)$ having special habit of medical importance in the form of heavy smoking.

Table (3): According to the operative timing and the start of the oral intake:

\begin{tabular}{|l|l|c|}
\hline \multicolumn{2}{|c|}{} & Total no. $=50$ \\
\hline \multirow{2}{*}{ Operative time (minute) } & Mean \pm SD & $68.60 \pm 18.79$ \\
& Range & $39-110$ \\
\hline \multirow{2}{*}{ Start Oral Intake } & Same day & $14(28.0 \%)$ \\
& Next day & $36(72.0 \%)$ \\
\hline
\end{tabular}

The operative time ranges between 39 minutes to 110 minutes from skin incision to closure with mean value of 68.60 and SD \pm 18.79, regarding the start of the oral intake only 14 patients (28\%) are able to start by the same day while 36 patients $(72 \%)$ started the next day.

Table (4): According to the other complications and the duration of stay in hospital:

\begin{tabular}{|l|l|c|}
\hline \multicolumn{2}{|l|}{} & $\begin{array}{c}\text { Total no. } \\
\mathbf{5 0}\end{array}$ \\
\hline \multirow{2}{*}{$\begin{array}{l}\text { Early } \\
\text { Complication }\end{array}$} & Negative & $46(92.0 \%)$ \\
& Wound infection & $3(6.0 \%)$ \\
& Organized & $1(2.0 \%)$ \\
\cline { 1 - 2 } $\begin{array}{l}\text { Hospital Stay } \\
\text { (days) }\end{array}$ & Mean \pm SD & $2.60 \pm 0.61$ \\
\hline & Range & $2-5$ \\
\hline
\end{tabular}

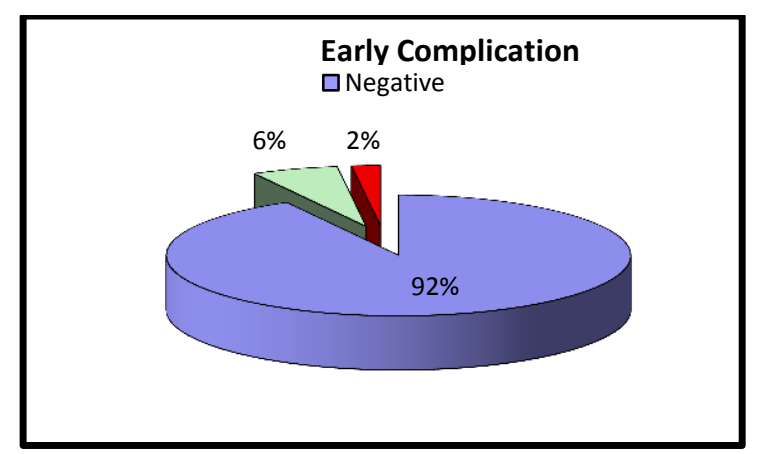

Figure (2): Early complication.

The previous table shows that among the studied patients only 3 patients (6\%) experienced wound infection, only 1 patient (2\%) experienced an organzied hematoma formation out of the 50 studied patients, all these infections were superficial infections properly treated by anibiotics and daily dressing. Regarding the hospital stay time it was ranged between 2 days to 5 days with mean value of 2.60 and $\mathrm{SD} \pm 0.61$ according to postoperative sequelae and post-operative pain.

Table (5): According to the suction drain and its amount and the time of removal.

\begin{tabular}{|l|l|c|}
\hline \multicolumn{2}{|l|}{} & $\begin{array}{c}\text { Total no. }= \\
\mathbf{5 0}\end{array}$ \\
\hline \multirow{3}{*}{ Suction drain } & Drain less & $25(50.0 \%)$ \\
& group & $25(50.0 \%)$ \\
\hline & Drained group & $250.80 \pm$ \\
Drain amount/24 hrs. & Mean \pm SD & 24.65 \\
(cc) & Range & $20-150$ \\
\hline $\begin{array}{l}\text { Drain Removal time } \\
\text { (days) }\end{array}$ & Mean \pm SD & $2.48 \pm 1.53$ \\
& Range & $1-7$ \\
\hline
\end{tabular}

The previous table showed that, the 50 patients were divided into 2 group of which 25 of them with suction drain and the other 25 with no suction drain. Among the drained group, the drained amount ranged from 20 C.C to 150 C.C sero-sangeonus to serous in nature with mean value of 50.80 and $\mathrm{SD} \pm 24.65$. Regarding to the drain removal time, it was ranged from 1 day to 7 days with mean value of 2.48 and $\mathrm{SD} \pm 1.53$. After drain removal the studied patients were observed for local drain site complications, however, no local early complications were detected.

Significant difference found to be between drained and drain-less patients as regarding:

- Age (Significantly drain-less patients are younger), however, further studies should be conducted using age as a fixed factor to determine its effect.

- Start of oral intake (significantly earlier in drain-less patients).

- Post-operative pain (significantly lowers in severity in drain-less patients). 
- Postoperative hospital stay (significantly shorter duration in drain-less patients)

\section{DISCUSSION}

More than half a million hernia operations are performed in the United States each year. Fourteen percent are umbilical hernias, with an incidence equal between male and female children, but, in adults, it is 3 times more common in women than in men. Ten percent are incisional hernias, with female to male ratio, 2:1. Epigastric hernias occur at a prevalence of $0.5 \%$ and are more common in males with male to female ratio 3:1. Spigelian hernias are rare and occur in persons aged approximately 50 years, with no sex or side predilection. Interparietal, and lumbar hernias are rare ${ }^{(14)}$.

Ventral hernias include all hernias in the anterior and lateral abdominal wall. Midline defects include umbilical, paraumbilical, epigastric, and hypogastric hernias. Umbilical hernias are by far the most common type of ventral hernias; they are usually small and are more common in women. Paraumbilical hernias are large abdominal defects through the linea Alba in the region of the umbilicus and are usually related to diastasis of the rectus abdominis muscles. Epigastric hernias and hypogastric hernias occur in the linea Alba above and below the umbilicus, respectively, lateral hernia include spiglian hernias which can occur anywhere along the length of the spigelian line ${ }^{(15)}$.

During the last few decades, the open surgical approach has been the standard technique for hernia repair. First it was done by sutures alone, which has several complications such as putting excessive strain on the surrounding tissues through which the sutures are passed and also has high recurrence rate. In order to provide better results and to decrease these complications, an alternative technique was developed in which there is a piece of synthetic mesh or screen material is applied $^{(16)}$.

Mesh placement in the priperitoneal, retro muscular sub-lay position with overlapping the hernia defect in all directions was introduced in the late 1980s, the refinement of sublay technique decreased the recurrence rates and gave better outcome making it to be declared the standard of care of ventral hernias ${ }^{(17,18)}$.

Hernia recurrence is a distressing event to patient and embarrassing to surgeons and tension free mesh repair is an ideal technique which has decreased the incidence of recurrence, the location of the reinforcement appears to influence outcomes. Underlay or retrorectus mesh placement is associated with lower recurrence rates ${ }^{(19,20)}$.

\section{CONCLUSION}

Sublay (retro-muscular) mesh repair is a good alternative to other repairs. This study advocates this method of PUH hernia repair as it is applicable mean of repair. The mesh is mostly hidden and anchored behind the rectus sheath, the complication rate is low, and there is a low recurrence rate. The use of suction remains controversial and still no definite indications to insert suction drain but its importance remain in high risk patients, we suggest carrying out more trials on retromuscular mesh repair, with the inclusion of a larger number of cases and a longer period of follow-up.

\section{Conflicts of interest}

None declared.

\section{REFERENCES}

1. Seker G, Kulacoglu H, Öztuna D et al. (2014): Changes in the frequencies of abdominal wall hernias and the preferences for their repair: a multicenter national study from Turkey. Int Surg.,99 (5):534-42. 
2. Dabbas N, Adams K, Pearson K, Royle G (2011): Frequency of abdominal wall hernias: is classical teaching out of date? JRSM., 2 (1):5.

3. Kulaçoğlu H (2015): Current options in umbilical hernia repair in adult patients. Ulus cerrahi Derg. Turkish Surgical Association, 31 (3):157-61.

4. Gray SH, Hawn MT, Itani K (2008): Surgical progress in inguinal and ventral incisional hernia repair. Surg Clin North Am., 88(1):17-26.

5. Singla $S$, Daspin $S$, Nittala $P$, John $P$ et al. (2013): spectrum of abdominal wall hernias and their types. Indian Journal of Medical Case Reports, 2: 69-70.

6. Mahadevan V (2013): Essential anatomy of the abdominal wall in management of abdominal hernias, edited by Kingsnorth AN and LeBlanc KA,Springer, London,fourth edition.

7. Ascar OM (1978): A new concept of the etiology and surgical repair of paraumbilical and epigastric hernias. Ann R Coll Surg. Engl., 60:42-48.

8. Mattix KD, Winchester PD, and Scherer LR et al. (2007): Incidence of abdominal wall defects is related to surface water atrazine and nitrate levels. J Pediatr Surg., 42(6): 947-9.

9. Ellis H (2007): Applied anatomy of abdominal incisions. Br J Hosp Med., 68:M22.

10. Flament JB (2006): Functional anatomy of the abdominal wall. Chirurg., 77(5):401-407.

11. Stylopoulos N and Rattner D (2005): The history of ventral hernia surgery from bowditch to laparoscopy. Ann Surg., 15: 185-193.

12. Mannien MJ, Lavonius M, Perhoniemi VJ et al. (2003): Results of incisional hernia repair: a retrospective study of 172 unselected hernioplasties. Eur J Surg., 157:29-31.

13. Ponten JE, Somers KY, Nienhuijs SW (2012): Pathogenesis of the epigastric hernia. Hernia., 16(6):627-33.

14. Ruhl CE and Everhart JE (2007): Risk factors for inguinal hernia among adults in the US population. Am J Epidemiology, 165(10):1154-61.

15. Singla $S$, Daspin $S$, Nittala $P$, and John $P$ et al. (2013): spectrum of abdominal wall hernias and their types. Indian Journal of Medical Case Reports, 2(2): 69-70.

16. Stylopoulos N and Rattner D (2005): The history of ventral hernia surgery from bowditch to laparoscopy. Ann Surg., 15(2):185-193.

17. Goda El-Santawy HM, El-Sisy AA, ElGammal AS, El-Kased AF, Sultan HM (2014): Evaluation of retromuscular mesh repair technique for treatment of ventral incisional hernia. Menoufia Med J., 27:226-9.

18. Oh T, Hollands MJ, Langcake ME, Parasyn AD (2004): Incisional hernia repair: a Retrospective review and early experience of laparoscopic repair. Surgery, 74(2):50-56.

19. Jat MA, Memon MR, Rind GH, Shah SQ (2011): Comparative evaluation of "Sublay" versus "Inlay" meshplasty in incisional and ventral hernias. Pak J Surg., 27(1):54-8.

20. Albino FP, Patel KM, Nahabedian MY, Sosin M, Attinger CE, Bhanot P (2013): Does mesh location matter in abdominal wall reconstruction? A systematic review of the literature and a summary of recommendations. Plast Reconstr Surg., 132(5):1295-304. 